\title{
The use and abuse of language in science
}

\author{
Alan O'Rourke Sheffield University
}

There exists a long running criticism of science that it is written in styles that are at best boring and at worst unintelligible. There is also a continuing battle between, on the one hand, the purists who delight in debating the terrors of split infinitives and double negatives and, on the other hand, those who believe that language needs to evolve organically, as long as most of the audience knows what it means. So, one side will tut-tut about phrases like "less unemployed people", and be shouted down as pedants, and the other side will say most folks get the gist, and be castigated for sloppiness.

We hear of university students who cannot express themselves in plain English; and of C P Snow's "two cultures", the literate but scientifically ignorant versus the technically well-versed who can communicate only in jargon, glaring at each other across the barricades. I recently assessed some scripts for a course: one student seemed unaware of apostrophes (or, being perhaps unsure of where to put them, had at least been consistent in omitting them totally); another employed capital initial letters erratically. I would certainly place myself on the side of the conservatives on one issue. Whatever else a country's education system achieves, it is a failure if it turns out students who cannot express themselves concisely and accurately in their own tongue. While accepting that there was a good deal of snobbish elitism in the "classical education", the underlying motives were often noble:

"The man we are proud to send forth from our Schools will be remarkable less for something he can take out of his wallet and exhibit for knowledge, than for being something, and that something recognisable for a man of unmistakable intellectual breeding whose trained judgement we can trust to choose the better and reject the worse."1

Furthermore, although you can bend the rules of grammar to some degree, sooner or later it makes what you write either ambiguous or incoherent. Most great authors can get away with some idiosyncrasies, if backed by a good working knowledge of how to use language precisely. Thus the school of thought which claims that it is wrong to end a sentence with a preposition attracted Winston Churchill's caustic comment: "This is the sort of English up with which I will not put". ${ }^{2}$

Maybe this is one of the greatest arguments against a narrow science-based secondary education: at a period in their lives when many young people may read little if any good quality fiction, they will have nothing to model their style upon but contemporary A-level textbooks. Yet there was time when those who ended up as scientists would still have had the benefit of a liberal education, studying history and the classics. I am willing to stick my neck out and say that when they came to write their papers, books and theses, their style was often much clearer than that of their modern counterparts. One possible solution might be to introduce some studies of the history of each discipline into the A-level curriculum, and expose students to examples of good quality prose from the history of their subject. For instance, from Sir Francis Bacon:

"Medicine is a science which hath been (as we have said) more professed than laboured, and yet more laboured than advanced; the labour having been, in my judgement, rather in a circle than in progression. For I find much iteration but small addition."”3

In the contemporary context, here are a few pet hates, accumulated over the years.

1. From an e-mail discussion group: We may need a more less focused approach.

(Would this be different from a "less more focused approach"?)

2. "Not un-" a supremely awkward construction: does "a not un-painted flagpole" mean painted; neither painted nor un-painted (maybe creosoted instead); that the author is unwilling to commit him or herself, or that he or she just cannot be bothered to go out and look at the pole? (As usual, this maybe a case of "do as I say, not as I write: Orwell once condemned the habit, and then slipped into a "not un-" a few pages on.) I have seen the following phrase in the editorial of a leading medical journal: "a not unimportant number of lives saved". To be fair, I think the author's first language may have been other than English, but I am still not sure what this phrase means. The possibilities include: an important number of lives saved; a number of important lives saved; a number of lives saved which does not reach statistical significance; a number of lives saved which is statistically, but not clinically significant; a small number of lives will be saved, but this is important, because any life saved is significant to the person who is saved; a number of lives saved which is neither important nor trivial: the impact of this intervention has not been properly evaluated yet 
3. This is the final ultimatum (what about the ultimatum before that?)

4. There are three alternatives. (Three choices or options possibly, but only two alternatives.)

5. From another e-mail message:

"We use following superlatives in describing occurrence of various medical conditions, processes etc etc, I will appreciate [sic] if members will [sic] be able to define these terms that we use on daily basis and will appreciate if you would be able to give a percentage point $(0-100 \%)$ for these terms. What do these term mean in day to day practice? (eg.: This symptom is not a common occurrence in such a such disease). Various superlatives are: commonly; uncommonly; not commonly; not uncommonly; rarely; frequently; not frequently; infrequently; not infrequently."

What is a "medical superlative"? According to the grammar learned at school, an adjective or an adverb could occur in three forms: basic, comparative, superlative.

Thus: Quick (adjective) Quicker (comparative) Quickest (superlative)

and: Quickly (adverb) More quickly (comparative) Most quickly (superlative)

I am therefore left wondering if this list is supposed to be a table of comparative terms, or some sort of approximations of frequencies, where, for argument's sake, "commonly" means in " $80 \%$ or more of cases". If so, what then does "not infrequently" mean? Frequently, not infrequently, neither frequently nor infrequently?

6. Another deplorable trend is the attempt to make something more significant than it really is. Sometimes this is plain ridiculous:

"There is now overwhelming anecdotal evidence that MMR does damage."

Isn't "overwhelming anecdotal evidence" a self contradiction? Anecdotal evidence should lead to a proper study (with a focused research question and an appropriate methodology) which may, but often do not, provide substantiated evidence. Maybe we are back in the realm of the opposition of some Victorian physicians to the use of ether and nitrous oxide to relieve the pain of childbirth, quoting the verses from Genesis, "in sorrow thou [Eve] shalt bring forth children" ${ }^{4}$ to substantiate their views. (I gather that Queen Victoria, who had nine children and started using analgesia about half way through her family was not impressed and kept asking for the gas.)
But, finally, there is a serious message. Among the threads running through the debate about the new National Health Service, is one of greater accountability, both to politicians and the public who use the health service. So, for instance, clinical governance annual reports must not only be available publicly, they must be comprehensible. Involving patients in decision making requires the presentation of research findings in plain English, with competent translations into other languages as needed. All this means writing good clear, unambiguous prose, with no jargon or acronyms that are not promptly explained, and which a twelve-yearold of average ability can understand. Here are a few personal recommendations. Avoid the passive tense like the plague, unless you have no option: do not write "the decision was made". Decisions do not make themselves. Who made the decision? Personal pronouns are acceptable: it is ridiculous to write about yourself in the third person. Avoid "not un-" phrases: say what you mean, rather than listing all the things you don't. Use short sentences. Call a spade a spade: if you need definitions make sure they clear the air, not muddy the water. Make sure you know what words mean: even if some of your audience are on your wavelength, others may get the wrong idea. A particular problem is "enormity". Many people now think it is some sort of noun derived from enormous, and use it to indicate the magnitude of the task facing them. As it actually means grossness and immorality, unless you work in the fraud squad, it can give others a very odd idea about what you spend your day doing.

Just for fun, whatever sins of commission or omission I may have accidentally included, there is one deliberate grammatical error in this piece. "Having eyes, see ye not?"

Alan O'Rourke is a Lecturer at the Institute of General Practice and Primary Care, Community Sciences Centre, Northern General Hospital, Sheffield University.

\section{References}

1 Quiller-Couch A. On the art of reading. Cambridge: Cambridge University Press, 1924: 10

2 Gowers E. Plain words: a guide to the use of English. London: HMSO, 1948: 74 .

3 Wright A. Bacon: the advancement of learning. Oxford: the Clarendon Press, 1900: 137.

4 Holy Bible Genesis 16: iv. (Authorised version).

5 Holy Bible St. Mark 18: viii. (Authorised version). 